\title{
Vigilância em saúde do trabalhador e promoção da saúde: aproximações possíveis e desafios
}

\author{
Worker's health surveillance and health promotion: \\ similarities and challenges
}

Roberta Belizário Alves 1

\footnotetext{
1 Centro de Estudos de Saúde do Trabalhador e Ecologia Humana, Escola Nacional de Saúde Pública, Fundação Oswaldo Cruz. Rua Leopoldo Bulhões 1480, Rio de Janeiro, $R J$ 21041-210, Brasil.
}

\begin{abstract}
This paper discusses the possible similarities between worker's health surveillance practices and the health promotion approach, as well as the differences and challenges of worker's health surveillance vis-à-vis this other public health concept, seeking to reflect on the pertinence, relevance, and feasibility of the health promotion perspective for Worker's Health. The author contends that there are many theoretical and methodological points in common between the two approaches and raises the need for Worker's Health Surveillance to incorporate Health Promotion activities more effectively in order to make Worker's Health Surveillance activities more effective and consolidate itself as a public health field.

Key words Surveillance; Occupational Health; Health Promotion

Resumo O trabalho pretende discutir as aproximações possíveis entre as práticas de Vigilância em Saúde do Trabalhador e o enfoque da promoção da saúde, bem como os distanciamentos $e$ desafios da Vigilância em Saúde do Trabalhador em face dessa outra concepção de saúde pública, procurando refletir sobre a pertinência, a relevância e a viabilidade de tal perspectiva para $a$ Saúde do Trabalhador. A discussão empreendida defende que existem muitos pontos em comum entre essas abordagens, em termos teóricos e metodológicos, e aponta a necessidade para a Vigilância em Saúde do Trabalhador de se integrar de forma mais efetiva às ações de promoção da saúde, a fim de a buscar uma maior viabilização de suas ações e sua consolidação como área da saúde pública.

Palavras-chave Vigilância; Saúde Ocupacional; Promoção da Saúde
\end{abstract}




\section{Introdução}

Em novembro de 1986, na cidade de Ottawa, Canadá, reunia-se a I Conferência Internacional sobre Promoção da Saúde. Essa conferência foi uma resposta à demanda crescente e imperiosa de uma nova concepção de saúde, que pudesse responder à complexidade emergente dos problemas de saúde da atualidade, cujo entendimento não é possível através do enfoque estritamente preventivista, que vincula determinada doença a determinado agente ou grupo de agentes, mas que se relaciona a questões como as condições e modos de vida.

Em face desses dilemas colocados atualmente para a sociedade, a saúde pública, para dar respostas a esses processos de saúde/doença em curso, reconhecidamente complexos e multifacetados, vem desenvolvendo uma discussão e uma experimentação em torno da idéia da promoção da saúde.

A Vigilância em Saúde do Trabalhador (VST) vem se firmando como uma área de atuação da saúde pública e, nesse sentido, necessita atentar para essas mudanças em curso nos processos de saúde/doença e na atuação da saúde pública em geral, a fim de poder dar respostas efetivas aos problemas colocados para os trabalhadores - problemas estes de ordem bastante complexa e de difícil resolução mediante unicamente ações curativas e preventivas.

É a partir do reconhecimento da necessidade de a VST refletir sobre suas práticas em face do novo enfoque da promoção da saúde que, no âmbito deste trabalho, pretende-se discutir as aproximações possíveis entre as práticas de VST e o enfoque da promoção da saúde, bem como os desafios da VST diante dessa nova concepção de saúde pública.

\section{O conceito ampliado de saúde}

O desenvolvimento conceitual e metodológico da saúde pública contemporânea, ligado aos avanços da bacteriologia e parasitologia, vem tradicionalmente se orientando basicamente por um conceito de saúde que corresponderia à ausência de doenças ou à noção de equilíbrio do organismo.

Por outro lado, Georges Canguilhem nos traz uma importante contribuição conceitual ao tratar o conceito de saúde de uma outra forma, colocando em xeque justamente essa concepção de saúde como oposto de doença. Canguilhem afirma que é valendo-nos de nossa capacidade para tolerar as infidelidades e variações do meio que devemos pensar o conceito de saúde. A saúde pode ser pensada como a possibilidade de cair enfermo e de poder recuperar-se, como uma guia reguladora das possibilidades de ação (Canguilhem, 1995; Caponi, 1997).

Falar de saúde como o conjunto dos poderes que nos permitem viver sob a imposição do meio - como colocado por Canguilhem (1995) - implica que as intervenções em saúde necessitam se orientar, não apenas a fim de impedir que a doença aconteça, mas também prover meios para que os indivíduos e grupos possam adoecer e recuperar-se. Dessa forma, adotando essa visão sobre saúde, as intervenções em saúde poderiam se orientar para ampliar ao máximo a margem de segurança e as possibilidades dos indivíduos para lidar com as infidelidades do meio. "Podemos falar de saúde quando temos os meios para enfrentar nossas dificuldades e nossos compromissos" (Canguilhem, 1995 apud Caponi, 1997:306).

O autor defende ainda que a saúde não pode ser concebida como um conceito científico, e, sim, vulgar, ou seja, ao alcance de todos. E isto porque a saúde implica uma experiência subjetiva vivenciada pelo sujeito, que não pode ser totalmente apreendida pelo conhecimento científico nem se pretender um conceito de valor universal (Caponi, 1997). Com isso, Canguilhem (1995) nos apresenta a possibilidade e a necessidade de tratar da questão da saúde através da participação de todos os atores da saúde, que vivenciam a experiência do processo saúde/doença, na produção de conhecimento e nas intervenções sobre este processo.

\section{A saúde pública e as práticas de promoção da saúde}

Em face dos desafios colocados atualmente pelos processos em curso de saúde/doença, a saúde pública vem repensando sua atuação com base na discussão acerca da promoção da saúde, que tem contribuído de forma importante no redirecionamento das práticas em saúde.

Este novo enfoque, que parte de uma concepção ampla do processo saúde-doença, aponta para os determinantes múltiplos da saúde e para a intersetorialidade, afirmando que os requisitos para a saúde são: paz, educação, habitação, alimentação, renda, ecossistema estável, recursos sustentáveis, justiça social e eqüidade (Buss, 2000).

A partir do momento em que se considera a saúde como algo mais amplo e não apenas a ausência de doenças, as estratégias de intervenção deslocam-se do eixo puramente indivi- 
dual para a atuação sobre esses diferentes elementos, o que demanda, necessariamente, a interdisciplinaridade e a intersetorialidade.

Teixeira et al. (1998), ao discutirem as alternativas da redefinição dos modelos assistenciais no SUS, apresentam o conceito de Vigilância da Saúde (VS) como alternativa aos modelos tradicionais em saúde pública, centrados na assistência médica e na erradicação e controle de doenças. Esta abordagem se apresenta como um modelo de operacionalização das idéias relacionadas à promoção da saúde.

A VS proposta por Teixeira et al. (1998) vai além da produção exclusiva de informações sobre o monitoramento de doenças específicas, em direção a uma outra abordagem dos problemas de saúde, que inclui a análise da situação de saúde da população, que não se refere apenas ao monitoramento de doenças, mas fundamentalmente à análise das condições de vida da população, em um território delimitado, abrangendo seus diversos aspectos - econômico, social, ambiental. Engloba, ainda, o planejamento, a programação e a execução das ações a serem empreendidas para o enfrentamento dos problemas de saúde, tomando como objeto de suas intervenções não apenas os riscos e os danos, mas também os determinantes destes e as necessidades de saúde (Teixeira et al., 1998).

\section{Vigilância em saúde do trabalhador e promoção da saúde: aproximações possíveis}

Os pressupostos teóricos e metodológicos que embasam as práticas em Saúde do Trabalhador (ST), em muitos aspectos, guardam alguns pontos em comum com a perspectiva da promoção da saúde e da VS.

Essas aproximações dizem respeito, em primeiro lugar, à concepção de saúde que orienta as práticas em ST. A VST, ao passo que sofre influências do movimento da saúde coletiva, da medicina social latino-americana e da reforma sanitária italiana, rompe com a abordagem hegemônica que vincula a doença a um agente específico ou a um grupo de agentes existentes no ambiente de trabalho (Dias, 1994). As intervenções em ST e, em particular, em VST se pautam na concepção de que a saúde para o trabalhador não significa apenas a ausência de doenças ocupacionais e acidentes de trabalho, mas também, e principalmente, a transformação dos processos de trabalho em seus diversos aspectos, na direção de buscar não apenas a eliminação de riscos pontuais que podem ocasio- nar agravos à saúde, mas também uma outra inserção do trabalhador no processo produtivo que seja potencializadora de saúde e de vida (Brito \& Porto, 1991).

Assim como no enfoque da promoção da saúde e da vigilância da saúde enfatiza-se o caráter de multideterminação do processo saúde/doença, que guarda relação com aspectos econômicos, sociais, políticos e ambientais, a ST e a VST concebem o processo saúde/doença como socialmente determinado (Laurell, 1987).

Com base nesse conceito ampliado de saúde, e similarmente ao enfoque da promoção da saúde, a ST elege como seu objeto de estudos não apenas os riscos e os agravos/efeitos para a saúde, mas também os determinantes de tais riscos e efeitos. Esses determinantes, em ST, traduzem-se no conceito de processo de trabalho, que na verdade torna-se o objeto de estudos e intervenção dessa área de atuação e que é responsável por tais riscos e agravos (Almeida, 2000).

Do mesmo modo que, para o encaminhamento e efetividade de ações de promoção da saúde, é defendida a participação da comunidade, a VST necessita invariavelmente estabelecer parcerias, principalmente com os trabalhadores, que são os maiores interessados.

Podemos citar, ainda, como um outro aspecto comum entre a ST e o enfoque da promoção da saúde, a necessidade e a busca pela interdisciplinaridade, já que o campo da ST é constituído por uma diversidade de saberes, oriundos de diversas áreas do conhecimento, que o constituem como campo interdisciplinar (Almeida, 2000).

\section{Considerações finais}

Um dos desafios que persistem ainda para a ST, tomando como referência o enfoque da promoção da saúde, diz respeito à concretização da intersetorialidade em suas práticas. No âmbito das ações em ST, persiste um conflito de competências entre os órgãos de vigilância, sendo necessário um maior diálogo entre os setores governamentais tradicionalmente vinculados a essas questões - o Ministério do Trabalho, o Ministério da Previdência e o Ministério da Saúde (Machado, 1997).

Porém a intersetorialidade não diz respeito apenas à ação conjunta de esferas distintas de governo, mas também à busca de parceria com outros setores não governamentais. É necessário aprofundar a integração com as organizações dos trabalhadores, além de outras organizações da sociedade civil, pois, afinal, as ques- 
tões de saúde dos trabalhadores não dizem respeito apenas aos trabalhadores em si, mas a todo o conjunto da população.

Partindo do pressuposto de que saúde, em seu sentido ampliado, significa os poderes que nos permitem viver no meio, incluindo trabalho, educação, cultura, moradia, saneamento, lazer, convívio social, ecossistema saudável, entre outras coisas, a ST necessita considerar que saúde dos trabalhadores não se remete apenas a problemas diretamente relacionados a aspectos do processo de trabalho no qual se insere e atuar sobre ela. Isso não significa dizer que a VST deva dar conta de todos esses fatores e agir sobre eles, e sim que deve procurar estabelecer parcerias, por meio da intersetorialida- de, a fim de buscar uma atuação mais abrangente e eficaz.

O enfoque da promoção da saúde e a proposta da vigilância da saúde vêm se colocando como um instrumento poderoso para que a ST possa integrar-se e sair do isolamento em que se encontra nas políticas públicas de saúde, por meio de sua inserção na proposição de políticas saudáveis, procurando mostrar que os problemas de saúde por essa área colocados não dizem respeito apenas aos trabalhadores, mas também ao meio ambiente e à população como um todo, em termos de condições de moradia e de saneamento, acesso à educação e a serviços de saúde, entre outras coisas.

\section{Referências}

ALMEIDA, G. E. S., 2000. Pra que Somar se a Gente Pode Dividir? Abordagens Integradoras em Saúde, Trabalho e Ambiente. Dissertação de Mestrado, Rio de Janeiro: Escola Nacional de Saúde Pública, Fundação Oswaldo Cruz.

BUSS, P. M., 2000. Promoção da saúde e qualidade de vida. Ciência \& Saúde Coletiva, 5:163-177.

BRITO, J. C. \& PORTO, M. F. S., 1991. Processo de Trabalho, Riscos e Cargas à Saúde. Rio de Janeiro: Centro de Estudos em Saúde do Trabalhador e Ecologia Humana, Escola Nacional de Saúde pública, Fundação Oswaldo Cruz. (mimeo.)

CANGUILHEM, G., 1995. O Normal e o Patológico. Rio de Janeiro: Forense Universitária.

CAPONI, S., 1997. Georges Canguilhem y el estatuto epistemológico del concepto de salud. História, Ciências, Saúde, 4:287-307.

DIAS, E. C., 1994. A Atenção à Saúde dos Trabalhadores no Setor Saúde (SUS), no Brasil: Realidade, Fantasia ou Utopia? Tese de Doutorado, Campinas: Faculdade de Ciências Médicas, Universidade Estadual de Campinas.
LAURELL, A. C. \& NORIEGA, M., 1987. Para o estudo da saúde na sua relação com o processo de trabalho. In: Processo de Produção e Saúde (A. C. Laurell \& M. Noriega, org.), pp. 99-137, São Paulo: Editora Hucitec.

MACHADO, J. M. H., 1997. Processo de vigilância em saúde do trabalhador. Cadernos de Saúde Pública, 13(Sup. 2):33-45.

TEIXEIRA, C. F.; PAIM, J. S. \& VILASBOAS, A. L., 1998. SUS, modelos assistenciais e vigilância da saúde. Informe Epidemiológico do SUS, 7:8-28.

Recebido em 14 de maio de 2001

Versão final reapresentada em 27 de março de 2002 Aprovado em 1 de julho de 2002 